\title{
Maternal diabetes status does not influence energy expenditure or physical activity in 5-year-old Pima Indian children
}

\author{
A.D. Salbe ${ }^{1}$, A.M. Fontvieille ${ }^{1}$, D.J. Pettitt ${ }^{2}$, E. Ravussin ${ }^{1}$ \\ ${ }^{1}$ Clinical Diabetes and Nutrition Section, National Institutes of Diabetes and Digestive and Kidney Diseases, National Institutes \\ of Health, Phoenix, Arizona, USA \\ ${ }^{2}$ Diabetes and Arthritis Epidemiology Section, National Institutes of Diabetes and Digestive and Kidney Diseases, National \\ Institutes of Health, Phoenix, Arizona, USA
}

\begin{abstract}
Summary Children of women who have diabetes during pregnancy are more likely to become obese by early adulthood than those of women with normal glucose tolerance during pregnancy. Obesity can result from either excess food intake, low levels of energy expenditure or both. In our study, we tested whether maternal diabetes status influences total energy expenditure (TEE by doubly labelled water), resting metabolic rate (RMR by ventilated hood) and physical activity level $(\mathrm{PAL}=\mathrm{TEE} / \mathrm{RMR}$ and assessed by activity questionnaire). Measurements were taken in 88 5-year-old Pima Indian children, 24 children of women with diabetes (2-h plasma glucose $\geq 11.1 \mathrm{mmol} / \mathrm{l}$ ) diagnosed before or during pregnancy and 64 children of women with normal glucose tolerance (2-h plasma glucose $<7.8 \mathrm{mmol} / \mathrm{l}$ during pregnancy and no prior history of abnormal glucose tolerance). Although birth weight was higher in children of diabetic than of nondiabetic women (mean $\pm \mathrm{SD}$; $3.8 \pm 0.6$ vs $3.5 \pm 0.4 \mathrm{~kg}, p<0.03$ ), there were no differences in weight $(26.4 \pm 6.9$ vs $24.2 \pm 5.6 \mathrm{~kg})$ or per
\end{abstract}

cent body fat $\left({ }^{18} \mathrm{O}\right.$ dilution; $33 \pm 8$ vs $\left.31 \pm 8 \%\right)$ between the groups at 5 years of age. There was no difference in TEE $(6508 \pm 1109$ vs $6175 \pm 942 \mathrm{~kJ} / \mathrm{d})$ or in RMR (4674 \pm 786 vs $4483 \pm 603 \mathrm{~kJ} / \mathrm{d})$ expressed as absolute values or after adjustment for weight and sex (TEE) or fat-free mass, fat mass, and sex (RMR). Physical activity level was also similar between the groups $(1.40 \pm 0.12$ vs $1.38 \pm 0.12)$. These results suggest that maternal diabetes status does not influence energy expenditure in the children by 5 years of age. Thus the greater obesity seen at older ages in the children of women with diabetes could be due to excess energy intake. Alternatively, if energy expenditure does have a role in the aetiology of obesity in these children, perhaps it does so only in older children. [Diabetologia (1998) 41: 1157-1162]

Keywords Gestational diabetes, energy metabolism, pre-school aged children, doubly labelled water, body composition.
The Pima Indians of Arizona have the world's highest reported prevalence of diabetes [1,2]; after 35 years of age, $50 \%$ of the population is reported to have diabetes [1]. We have found that at each age, both the prevalence and incidence of diabetes is higher than

Received: 14 November 1997 and in final revised form: 2 June 1998

Corresponding author: A.D. Salbe, PhD; NIH, NIDDK, CDNS; 4212 N 16th Street, Rm 541; Phoenix, AZ 850165319, USA

Abbreviations: RMR, Resting metabolic rate; TEE, total energy expenditure; PAL, physical activity level. earlier in our studies, resulting in more people with diabetes at earlier ages. As the age of onset of diabetes decreases, more women of childbearing age have Type II (non-insulin-dependent) diabetes or are at risk of developing gestational diabetes, which results in larger babies at birth [3-5]. Obesity, in turn, predisposes the children of women with diabetes to developing diabetes themselves, thus resulting in a "crossgenerational vicious cycle" [6] whereby successive generations of women are at greater risk of already being obese and having diabetes at childbearing age than the preceding generation.

In healthy, nondiabetic women, normal pregnancy is associated with insulin resistance, hyperinsulin- 
aemia, lower fasting glucose concentrations, and increased concentrations of non-esterified fatty acids and triglycerides $[7,8]$. These responses seem to be mediated by placental hormones including human placental lactogen, progesterone, prolactin, and cortisol [9]. Healthy women adapt to these metabolic abnormalities by increasing insulin secretion. In contrast, women who develop gestational diabetes or who have Type II diabetes during pregnancy exhibit the same degree of insulin resistance in the late stages of pregnancy, but a lower insulin secretory response, than do nondiabetic women [10]. As a result, the intrauterine environment in gestational diabetes is characterized by increased concentrations of glucose, amino acids and lipids in the maternal circulation, greater delivery of these nutrients to the fetus, raised fetal insulin secretion, and accelerated fetal growth $[11,12]$. Because differentiation of adipose tissue and storage of triglycerides begins during the third trimester of pregnancy [13], the effect of diabetes at this point in fetal development is to hasten the accumulation of fat in the fetus and results in infants that are both heavier and fatter than infants born to nondiabetic women [14].

We have reported previously that excessive obesity at birth among the babies of Pima Indian women with diabetes during pregnancy continues on into childhood, adolescence and early adulthood $[15,16]$. At 5-14 years of age, children born to women with diabetes who were of normal weight at birth were found to have relative weights $20 \%$ greater than children born to women who were normoglycaemic during pregnancy. These results suggest that maternal diabetes status is predictive of overweight, independently of birth weight [16]. Obesity and overweight result from an imbalance in the energy expenditure equation such that either food intake is in excess, energy expenditure is at a deficit, or both. The aim of this study was to determine the effect of maternal diabetes status on total energy expenditure, resting metabolic rate, and energy expended in activity in 5year-old Pima Indian children, the hypothesis being that if differences in energy expenditure were the cause of the obesity, children born to women with diabetes would have lower rates of energy expenditure than children born to normoglycaemic women.

\section{Subjects and methods}

From a group of 210 Pima Indian children $(5.5 \pm 0.3$ years) studied during the summer months of 1991-1996 at the National Institutes of Health Field Clinic located in the Gila River Indian Community in Sacaton, Arizona (40 miles southeast of Phoenix), 88 children were selected on the basis of maternal diabetes status (see below). A previous report on energy expenditure and activity levels in these children contains some of the data presented here [17]. Pima Indian children were of full Indian heritage and at least $50 \%$ Pima or Tohono O'od- ham heritage or both. Children arrived at the clinic at 08.00 hours in the fasted state, accompanied by one of their parents. Their health status was determined by medical history and physical examination and only healthy children were studied. Children reported to the clinic after a 10-h overnight fast on two occasions, one week apart, for approximately $6 \mathrm{~h}$ at the first visit and for approximately $3 \mathrm{~h}$ at the second visit. Before participation, volunteers and their parents were fully advised of the nature and purpose of the study and informed consent and assent were obtained. The experimental protocol was approved by the Institutional Review Board of the National Institute of Diabetes and Digestive and Kidney Diseases and the Tribal Council of the Gila River Indian Community.

Maternal diabetes status. As part of our ongoing studies of the Pima Indians, community residents are invited to participate in a formal medical evaluation including an oral glucose tolerance test every 2 years. As a result of this rigorous and regular screening, we are able to diagnose a large number of women with diabetes prior to pregnancy who would otherwise be found to have gestational diabetes.

Maternal diabetes status was assessed by oral glucose tolerance test using a 75-g glucose load during the last 180 days of pregnancy according to World Health Organization standards (2-h plasma glucose $\geq 11.1 \mathrm{mmol} / \mathrm{l}$ ) [18]. Women were considered to be normoglycaemic if the 2 -h plasma glucose concentration was less than $7.8 \mathrm{mmol} / \mathrm{l}$ and there was no prior history of abnormal glucose tolerance. Of the 210 children 24 were found to be from women with diabetes ( 22 diagnosed prior to pregnancy and 2 during the pregnancy) and 64 children were found to be from women who had documented normal glucose tolerance during the pregnancy, resulting in a total sample of 88 children. The remaining 122 children were not included in this study either because their mothers were found to have impaired glucose tolerance prior to or during the pregnancy under consideration or because their mothers had no documented glucose tolerance test during this pregnancy.

Body composition. Anthropometric and body composition measurements including height, weight and skin fold thicknesses were taken in the children during both clinic admissions as described previously $[17,19]$. Results represent the means of the two measurements. Relative weight was calculated as a percentage of an age-sex- and height-specific standard [20]. Body water, calculated from ${ }^{18} \mathrm{O}$ dilution spaces and from bioelectrical resistance, was used to assess body composition.

Total energy expenditure. Assessment of total energy expenditure (TEE) by the doubly labelled water method was made as described previously [17, 19, 21]. Briefly, after providing two baseline urine samples, children were asked to drink a solution containing $0.132 \mathrm{~g} 100 \%{ }^{2} \mathrm{H}_{2} \mathrm{O} / \mathrm{kg}$ total body weight (Isotec, Inc., Miamisburg, Ohio, USA) and $2.508 \mathrm{~g} 10 \% \mathrm{H}_{2}$ ${ }^{18} \mathrm{O} / \mathrm{kg}$ total body weight (Isotec Inc.). Complete urine collections were made at approximately $1.5,2.5,3.5$, and $4.5 \mathrm{~h}$ after dosing on day 1 and twice during a 3-h period 7 days later. The urine sample at $1.5 \mathrm{~h}$ was discarded to allow for equilibration of the isotope in the body water pool. The disappearance rates of the two stable isotopes were determined as described previously [21] from two early urine samples collected at 3.5 and $4.5 \mathrm{~h}$ and the two samples collected 7 days later. Carbon dioxide production was determined and total energy expenditure (TEE) calculated using a respiratory quotient of 0.866 [19].

Resting metabolic rate. After drinking the doubly labelled water, the children rested comfortably on a bed for $10 \mathrm{~min}$ after 
Table 1. Physical characteristics of 5-year-old Pima Indian children of normoglycaemic and diabetic mothers

\begin{tabular}{|c|c|c|c|}
\hline & $\begin{array}{l}\text { Children of normoglycaemic mothers } \\
(n=64)\end{array}$ & $\begin{array}{l}P \\
(\text { when }<0.10)\end{array}$ & $\begin{array}{l}\text { Children of diabetic mothers } \\
(n=24)\end{array}$ \\
\hline Sex (boys/girls) & $31 / 33$ & & $13 / 11$ \\
\hline Birth Weight (kg) & $3.5 \pm 0.4(2.8-4.4)$ & 0.03 & $3.8 \pm 0.6(2.8-4.9)$ \\
\hline Weight (kg) & $24.2 \pm 5.6(17.6-39.7)$ & & $26.4 \pm 6.9(15.4-42.9)$ \\
\hline Height $(\mathrm{cm})$ & $115.1 \pm 4.7(105-126)$ & & $115.8 \pm 5.5(103-123)$ \\
\hline Relative weight ${ }^{\mathrm{a}}(\%)$ & $118 \pm 21(91-186)$ & 0.08 & $127 \pm 25(95-189)$ \\
\hline Per cent body fat ${ }^{\mathrm{b}}\left({ }^{18} \mathrm{O}\right)$ & $31 \pm 8(18-46)$ & & $33 \pm 8(20-50)$ \\
\hline Sum of skinfolds (mm) & $72 \pm 31(27-160)$ & & $77 \pm 34(29-164)$ \\
\hline Fasting plasma glucose $(\mathrm{mmol} / \mathrm{l})$ & $4.5 \pm 0.4(3.4-5.4)$ & & $4.6 \pm 0.4(3.7-5.2)$ \\
\hline Fasting plasma insulin (pmol/l) & $50 \pm 44(6-240)$ & & $48 \pm 52(6-228)$ \\
\hline Fasting plasma leptin (ng/ml) & $4.3(0.6,42.5)$ & & $6.1(0.4,41.3)$ \\
\hline
\end{tabular}

Values represent means \pm SD and numbers in parentheses represent the range of values except in the case of leptin where the median and $95 \%$ CI values are presented

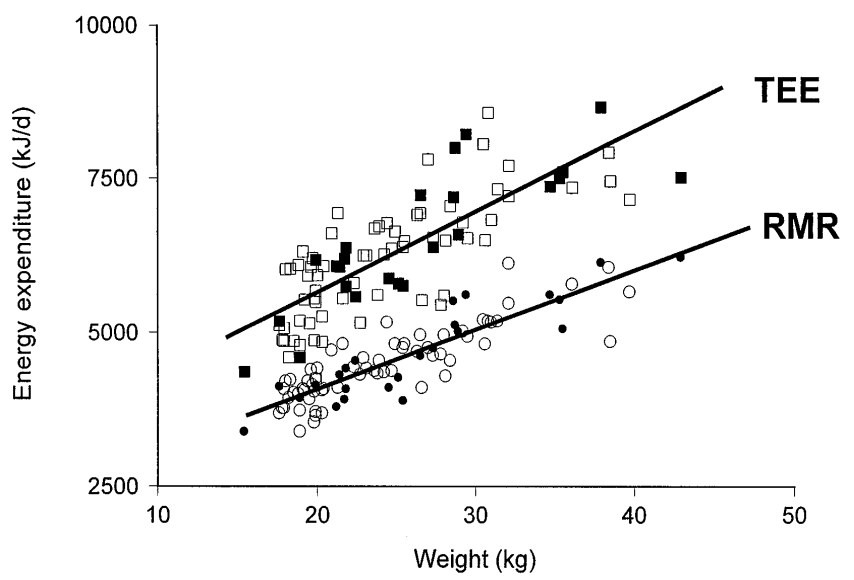

Fig. 1. Relation of total energy expenditure (TEE) and resting metabolic rate (RMR) and body weight. TEE, measured using the doubly labelled water method, is shown for children of normoglycaemic $(\square)$ and diabetic women ( $\square$ ). RMR, measured using indirect calorimetry, is also shown for children of normoglycaemic $(\bigcirc)$ and diabetic women

which the resting metabolic rate (RMR) was measured for 20 min using a DeltaTrac Metabolic Monitor (SensorMedics Corporation, Yorba Linda, Calif., USA) as described previously $[19,22]$. The RMR measurement was repeated at the return visit and results represent the mean of the two values.

Physical activity. Physical activity level was calculated as the ratio of TEE to RMR (PAL) and also assessed by activity questionnaire [23, 24].

Analytical measurements. Immediately after the RMR measurement, blood samples were drawn while the child was still in the fasted state. Plasma glucose concentrations were measured using the glucose oxidase method (Beckman Instruments Inc., Fullerton, Calif., USA). Plasma insulin concentrations were measured by an automated radioimmunoassay technique (ICN Biochemicals, Costa Mesa, Calif., USA). Plasma leptin concentrations were measured in duplicate in a solid phase sandwich enzyme immunoassay using affinity purified polyclonal and monoclonal antibodies (AMGEN, Inc., Thousand Oaks, Calif., USA).
${ }^{a}$ Relative weight based on a reference population described by Jelliffe [20]

${ }^{\mathrm{b}}$ Per cent body fat estimated from total body water determined by isotopic dilution

Statistical methods. Throughout the text, the data are expressed as means \pm 1 SD or as the median and $50 \%$ confidence intervals for activities derived from the questionnaire. Single and multiple linear regression analyses were performed using the general linear models procedure of the SAS Institute (Cary, N. C., USA). Pearson correlations were calculated between the physical characteristic and energy expenditure variables. The Wilcoxon 2-sample test was used to test differences between the groups in the responses to the activity questionnaire. Insulin and leptin values were $\log$ transformed $\left(\log _{10}\right)$ to make the distributions normal before analysis.

\section{Results}

The children's characteristics are shown in Table 1. Birth weight was higher $(p<0.03)$ in the children of women with diabetes compared with normoglycaemic women and this difference was largely because of the difference between the boys. Multiple linear regression analysis of the determinants of birth weight found that gestational age and maternal diabetes status were significant factors affecting birth weight in this cohort. Neither maternal age, height, smoking status, nor parity were significant determinants of birth weight. Despite the differences in birth weight, there were no significant differences between the groups in regard to any of the other characteristics at 5 years of age, including fasting plasma glucose, insulin, and leptin concentrations. The $9 \%$ difference in relative weight between the two groups approached significance $(p=0.08)$, suggesting a trend toward increased relative weight in the children born to women with diabetes.

Figure 1 shows the results of the energy expenditure measurements in the 88 children plotted against body weight. There were no significant differences between the groups in either TEE or RMR expressed as absolute values (Table 2) or after adjustment for weight and sex (TEE) or fat-free mass, fat mass, and sex (RMR). There were no significant differences be- 
Table 2. Energy expenditure and physical activity of 5-year-old Pima Indian children of normoglycaemic and diabetic mothers

\begin{tabular}{|c|c|c|c|}
\hline & $\begin{array}{l}\text { Children of normoglycaemic mothers } \\
(n=64)\end{array}$ & $\begin{array}{l}P \\
(\text { when }<0.10)\end{array}$ & $\begin{array}{l}\text { Children of diabetic mothers } \\
(n=24)\end{array}$ \\
\hline Resting metabolic rate $(\mathrm{RMR}, \mathrm{kJ} / \mathrm{d})$ & $4483 \pm 603$ & & $4674 \pm 786$ \\
\hline Total energy expenditure (TEE, $\mathrm{kJ} / \mathrm{d}$ ) & $6175 \pm 942$ & & $6508 \pm 1109$ \\
\hline $\begin{array}{l}\text { Activity energy expenditure (AEE) } \\
\left.\left.\text { [TEE-(RMR+TEF })^{a}\right) ; \mathrm{kJ} / \mathrm{d}\right]\end{array}$ & $1074 \pm 507$ & & $1183 \pm 499$ \\
\hline $\begin{array}{l}\text { Physical activity level (PAL) } \\
\text { (TEE/RMR) }\end{array}$ & $1.38 \pm 0.12$ & & $1.40 \pm 0.12$ \\
\hline $\begin{array}{l}\text { Recreational activities } \\
\text { (h played/wk) }\end{array}$ & $13(5,25)$ & 0.05 & $5(4,12)$ \\
\hline $\begin{array}{l}\text { Television/video watching } \\
\text { (h/d) }\end{array}$ & $4(2,5)$ & & $2(2,4)$ \\
\hline $\begin{array}{l}\text { Sleeping } \\
\text { (h/d) }\end{array}$ & $9(8,10)$ & & $9(8,10)$ \\
\hline $\begin{array}{l}\text { Parental activity rating }{ }^{\mathrm{b}} \\
(0=\text { inactive }-3=\text { rigorous })\end{array}$ & $2(1,3)$ & & $2(1,3)$ \\
\hline
\end{tabular}

tween the groups in energy expenditure for physical activity (the difference between the two curves depicted in Fig. 1) or in PAL (TEE/RMR, Table 2). Although fasting plasma concentrations of glucose, insulin and leptin were significantly correlated to TEE and RMR, these relationships were no longer significant after adjustment of the energy expenditure variables for body weight/body composition (data not shown).

Responses to the activity questionnaire are shown in Table 2. Children born to women with diabetes reportedly engaged in significantly fewer hours of recreational activity per week $(5 \mathrm{~h} / \mathrm{wk})$ than children of normoglycaemic women $(13 \mathrm{~h} / \mathrm{wk}, p=0.05)$. There were no significant differences, however, between the groups in the amount of time children were reported to spend sleeping, napping, or watching television and playing computer or video games. In addition, parents of both groups rated their children as similarly active.

\section{Discussion}

In our study, maternal diabetes status had no effect on TEE, RMR, energy expenditure for physical activity or PAL in Pima Indian children at 5 years of age. This refutes our hypothesis proposing lower rates of energy expenditure in children of women with diabetes and suggests that the greater obesity seen in these children at a later age can be due to excess energy intake. We were also concerned, however, that we might have been attempting to discern differences in energy expenditure too small to measure with current techniques. In a large cohort $(n=273)$ of 5-year-old children without energy expenditure measurements (unpublished observations), we found that growth from birth to 5 years of age was $21.9 \mathrm{~kg}$ in the children of women with diabetes $(n=35)$ and $17.9 \mathrm{~kg}$ in those of normoglycaemic women $(n=238)$, a difference of only $4.0 \mathrm{~kg}$ over 5 years. If we consider that $25 \%$ of this weight is deposited as fat-free mass (energy cost of $9.2 \mathrm{~kJ} / \mathrm{g}$ ) and $75 \%$ as fat mass (energy cost of $54.4 \mathrm{~kJ} / \mathrm{g}$ ), then the approximate energy value of this difference in weight gain amounts to $172 \mathrm{MJ}$ deposited over 5 years or just 94 $\mathrm{kJ} / \mathrm{d}(23 \mathrm{kcal} / \mathrm{d})$. We performed a post hoc sample size calculation and found that we needed 37 subjects in each group to detect differences this small. It appears then that with our sample sizes of 24 and 64 we did, in fact, have the power to detect these very small differences in daily energy expenditure.

We did find that children of women with diabetes spent fewer hours engaged in recreational sports activities over the previous year (as reported by questionnaire) than did children of normoglycaemic women, although both groups of children chose the same number of activities. Goran et al. [25] report that a small portion of the variance in body fat mass in similarly aged children could be explained by the amount of time devoted to physical activity, despite finding no effect of activity on energy expenditure measured using doubly labelled water. These authors hypothesize that perhaps long bouts of sustained, low intensity physical activity may be important in maintaining energy stores.

The small differences in birth weight found between the two groups could reflect improved standards of care for women with diabetes during pregnancy. Since the mid-1980s, the Indian Health Service has encouraged women with diabetes to moderate their weight gain, insulin treatment is routinely 
given as needed, and family planning practices emphasize the need for women to achieve normal blood glucose concentrations before becoming pregnant. Despite these differences in birth weight, we found no differences in body weight (although there was a trend towards raised relative weight) at 5 years of age in children of women with diabetes as compared with those of normoglycaemic women, despite our previous reports $[5,15]$. It will be important to see whether differences in birth weight between children of diabetic and nondiabetic mothers disappear as a result of better care.

We must also point out, however, that in our previous studies, 5-year-old children were not considered separately but were included in a much larger group of 5- to 9-year-old children. These younger children may not yet have reached the critical period of "adiposity rebound" [26, 27] when body mass index (weight/height ${ }^{2}$ ) begins to increase. Differences in weight found by age 10 years might not yet be apparent at this age. The differences in weight found at later ages in children of women with diabetes may be due to what Dietz [28] calls "entrainment" of appetite regulation or adipocyte number or both during the intrauterine period, possibly as a consequence of the differentiation of the hypothalamic centres responsible for control of food intake [29]. However, using twin analysis to control for genetic factors, Allison et al. [30] argue that intrauterine influences on birth weight do not have an enduring effect on adult weight independent of height, suggesting that the intrauterine environment entrains height, but not weight.

We have reported previously that several factors predispose people to gaining weight, including a low resting metabolic rate [31], low sympathetic nervous system activity [32, 33], low levels of spontaneous physical activity [34], and a high respiratory quotient indicating low levels of fat oxidation [35]. Since we saw no differences in energy expenditure between these groups, it could well be that the obesity seen in children of women with diabetes during pregnancy at a later age is due to increased food intake. In children with a familial history of obesity, the obesitypromoting effect of dietary fat seems particularly evident [36] and could be at play in our study group. Longitudinal follow-up studies in these children could help discern the causes of obesity in children of women with diabetes.

Acknowledgements. We gratefully acknowledge Kristan Anderson, Kathleen Woolf, Frank Gucciardo, Michael Milner, John Graves and the NIH dietary staff, and Vicky Andre, Sonja Antone and the staff of the NIH Field Clinic in Sacaton, Arizona, for their valuable assistance on this project. Most of all, we thank the volunteers and their families for their participation.

\section{References}

1. Knowler WC, Pettitt DJ, Saad MF, Bennett PH (1990) Diabetes mellitus in the Pima Indians: incidence, risk factors and pathogenesis. Diabetes Metab Rev 6: 1-27

2. Knowler WC, Pettitt DJ, Saad MF et al. (1991) Obesity in the Pima Indians: its magnitude and relationship with diabetes. Am J Clin Nutr 53: 1543S-1551S

3. Farquar JW (1959) The child of the diabetic woman. Arch Dis Child 34: 76-96

4. Pettitt DJ, Knowler WC, Baird HR, Bennett PH (1980) Gestational diabetes: Infant and maternal complications of pregnancy in relation to third-trimester glucose tolerance in the Pima Indians. Diabetes Care 3: 458-464

5. Pettitt DJ, Baird HR, Aleck KA, Bennett PH, Knowler WC (1983) Excessive obesity in offspring of Pima Indian women with diabetes during pregnancy. N Engl J Med 308: 242-245

6. Pettitt DJ, Knowler WC (1988) Diabetes and obesity in the Pima Indians: A cross-generational vicious cycle. J Obesity Weight Regul 7: 61-75

7. Kühl C (1991) Insulin secretion and insulin resistance in pregnancy and GDM. Diabetes 40 [Suppl 2]:18-24

8. Buchanan TA (1996) Intermediary metabolism during pregnancy: implications for diabetes mellitus. In: LeRoith D, Taylor SI, Olefsky JM (eds) Diabetes Mellitus. A Fundamental and Clinical Text. Lippincott-Raven, Philadelphia, pp 677-684

9. Freinkel N (1980) Banting Lecture 1980: Of pregnancy and progeny. Diabetes 29: 1023-1035

10. Buchanan TA, Metzger BE, Freinkel N, Bergman RN (1990) Insulin sensitivity and $\beta$-cell responsiveness to glucose during late pregnancy in lean and moderately obese women with normal glucose tolerance or mild gestational diabetes. Am J Obstet Gynecol 162: 1008-1014

11. Hollingsworth DR (1983) Alterations of maternal metabolism in normal and diabetic pregnancies: differences in insulin-dependent, non-insulin-dependent, and gestational diabetes. Am J Obstet Gynecol 146: 417-429

12. Buchanan TA (1996) Effects of maternal diabetes on intrauterine development. In: LeRoith D, Taylor SI, Olefsky JM (eds) Diabetes Mellitus. A Fundamental and Clinical Text. Lippincott-Raven, Philadelphia pp 685-695

13. Gellis SS, Hsia DYY (1959) The infant of the diabetic mother. Am J Dis Child 97: 1-41

14. Plagemann A, Harder T, Kohlhoff R, Rohde W, Dorner G (1997) Overweight and obesity in infants of mothers with long-term insulin dependent diabetes or gestational diabetes. Int J Obesity 21: 451-456

15. Pettitt DJ, Bennett PH, Saad MF, Charles MA, Nelson RG, Knowler WC (1991) Abnormal glucose tolerance during pregnancy in Pima Indian women. Long-term effect on offspring. Diabetes 40 [Suppl 2]:126-130

16. Pettitt DJ, Knowler WC, Bennett PH, Aleck KA, Baird HR (1987) Obesity in offspring of diabetic Pima Indian women despite normal birth weight. Diabetes Care 10: $76-80$

17. Salbe AD, Fontvieille AM, Harper IT, Ravussin E (1997) Low levels of physical activity in 5-year old children. J Pediatr 131: 423-429

18. World Health Organization, Study Group Diabetes Mellitus (1985) Technical Report Series No 727, WHO, Geneva, pp 9-14

19. Fontvieille AM, Harper IT, Ferraro RT, Spraul M, Ravus$\sin$ E (1993) Daily energy expenditure by five-year-old children, measured by doubly labeled water. J Pediatr 123: 200-207 
20. Jelliffe DB (1966) The assessment of the nutritional status of the community; with special reference to field surveys in developing regions of the world. World Health Organization, Monograph series No 53, Geneva

21. Ravussin E, Harper IT, Rising R, Bogardus C (1991) Energy expenditure by doubly labeled water: validation in lean and obese subjects. Am J Physiol 261:E402-E409

22. Fontvieille AM, Dwyer J, Ravussin E (1992) Resting metabolic rate and body composition in Pima Indian and Caucasian children. Int J Obesity 16: 535-542

23. Fontvieille AM, Kriska A, Ravussin E (1993) Decreased physical activity in Pima Indian compared with Caucasian children. Int J Obesity 17: 445-452

24. Kriska AM, Knowler WC, LaPorte RE et al. (1990) Development of questionnaire to examine the relationship of physical activity and diabetes in Pima Indians. Diabetes Care 15: 401-411

25. Goran MI, Hunter G, Nagy TR, Johnson R (1997) Physical activity energy expenditure and fat mass in young children. Int J Obesity 21: 171-178

26. Rolland-Cachera MF, Deheeger M, Bellisle F, Sempe M, Guilloud-Bataille M, Patois E (1984) Adiposity rebound in children: a simple indicator for predicting obesity. Am J Clin Nutr 39: 129-135

27. Rolland-Cachera MF, Deheeger M, Guilloud-Bataille M, Avons P, Patois E, Sempe M (187) Tracking the development of adiposity from one month of age to adulthood. Ann Hum Biol 14: 219-229

28. Dietz WH (1994) Critical periods in childhood for the development of obesity. Am J Clin Nutr 59: 955-959
29. Ravelli G-P, Stein ZA, Susser MW (1976) Obesity in young men after famine exposure in utero and early infancy. $\mathrm{N}$ Engl J Med 295: 349-353

30. Allison DB, Paultre F, Heymsfield SB, Pi-Sunyer FX (1995) Is the intrauterine period really a critical period for the development of adiposity? Intl J Obesity 19: 398-402

31. Ravussin E, Lillioja S, Knowler WC et al. (1988) Reduced rate of energy expenditure as a risk factor for body-weight gain. N Engl J Med 318: 467-472

32. Spraul M, Ravussin E, Fontvieille AM, Rising R, Larson DE, Anderson EA (1993) Reduced sympathetic nervous activity. A potential mechanism predisposing to body weight gain. J Clin Invest 92: 1730-1735

33. Tataranni PA, Young JB, Bogardus C, Ravussin E (1997) A low sympathoadrenal activity is associated with body weight gain and development of central adiposity in Pima Indian men. Obesity Res 5: 341-347

34. Zurlo F, Ferraro RT, Fontvieille AM, Rising R, Bogardus C, Ravussin E (1992) Spontaneous physical activity and obesity: cross sectional and longitudinal studies in Pima Indians. Am J Physiol 263:E296-E300

35. Zurlo F, Lillioja S, Esposito-Del Puente A et al. (1990) Low ratio of fat to carbohydrate oxidation as a predictor of weight gain: study of 24-h RQ. Am J Physiol 259:E650-E657

36. Eck LH, Klesges RC, Hanson CL, Slawson D (1992) Children at familial risk for obesity: an examination of dietary intake, physical activity and weight status. Int $\mathbf{J}$ Obesity 16: $71-78$ 